\title{
Высоковольтные 4H-SiC диоды Шоттки с полевой обкладкой
}

\author{
( П.А. Иванов, Н.М. Лебедева , Н.Д. Ильинская, М.Ф. Кудояров, Т.П. Самсонова, \\ О.И. Коньков, Ю.М. Задиранов
}

Физико-технический институт им. А.Ф. Иоффре Российской академии наук, 194021 Санкт-Петербург, Россия

`E-mail: Natali_lebedeva@mail.ioffe.ru

Поступила в Редакцию 1 октября 2020 г.

В окончательной редакции 12 октября 2020 г.

Принята к публикации 12 октября 2020 г.

\begin{abstract}
Изготовлены высоковольтные (2000 В) 4H-SiC диоды с барьером Шоттки. Для подавления преждевременного краевого пробоя на периферии активной области диодов формировалась полевая обкладка, диэлектрическим слоем в которой служит полуизолирующий $4 H-\mathrm{SiC}$, созданный с помощью облучения высокоэнергетичными (53 МэВ) ионами аргона. Для маскирования активных областей диодных структур от облучения на шоттки-контактах локальным гальваническим осаждением выращивались никелевые столбики с вертикальными стенками высотой 10-12 мкм. Сравнение вольт-амперных характеристик диодов с обкладкой и контрольных диодов без обкладки показало, что после облучения прямые вольт-амперные характеристики практически не изменяются, в то время как обратные вольт-амперные характеристики кардинально улучшаются. При этом вольт-амперные характеристики облученных диодов как в прямом, так и в обратном направлении хорошо описываются по классической теории термоэмиссии, если дополнительно учитывается понижение высоты барьера с ростом изгиба энергетических зон в полупроводнике.
\end{abstract}

Ключевые слова: карбид кремния, диод Шоттки, полевая обкладка, имплантация аргона.

DOI: 10.21883/FTP.2021.02.50507.9528

\section{1. Введение}

Карбид кремния политипа $4 H(4 H-\mathrm{SiC})$ благодаря своим уникальным электронным и тепловым свойствам является перспективным материалом для силовой электроники [1]. Ключевой проблемой при создании высоковольтных $4 H$-SiC приборов является устранение преждевременного краевого пробоя в обратном направлении. Для планарных 4H-SiC диодов Шоттки (ДШ) было предложено множество конструктивно-технологических решений проблемы краевого пробоя, в том числе формирование полевой обкладки, в которой изолирующий высокоомный слой формируется с помощью ионной имплантации аргона [1,2] или бора [3-6] (рис. 1).

В цитированных работах использовались ионы средних энергий (до 100 кэВ), так что толщина имплантированных слоев не превышала 1 мкм. Этого было достаточно, чтобы существенно поднять блокируемое диодом напряжение, однако предпробойные токи утечки оставались избыточными. Улучшить характеристики $4 H$-SiC ДШ с имплантированным изолирующим слоем в полевой обкладке можно путем формирования более глубокой изолирующей области с помощью облучения высокоэнергетичными ионами. Если толщина изолятора в структуре полевой обкладки будет сравнима с толщиной блокирующей $n$-базы, то напряжение пробоя диода может быть приближено в принципе к теоретическому пределу для одномерной барьерной структуры. В высоковольтных $4 H$-SiC ДШ с напряжением пробоя 1000-3000 В толщина блокирующей $n$-базы составляет 6-20 мкм (рис. 2). Ранее нами была показана возможность создания в $n-4 H-\mathrm{SiC}$ с концентрацией доноров $\sim 10^{16} \mathrm{~cm}^{-3}$ приповерхностных полуизолирующих слоев $i-4 H-\mathrm{SiC}$ толщиной $\sim 10$ мкм с помощью облучения высокоэнергетичными (53 МэВ) ионами аргона [7]. Необходимая для создания полуизолятора доза облучения была относительно невелика: $\sim 10^{12} \mathrm{~cm}^{-2}$. При комнатной температуре удельное сопротивление имплантированных аргоном $i$-слоев составляет $\sim 10^{13} \mathrm{OM} \cdot$ см. Как было показано, за компенсацию донорной проводимости ответственны радиационные дефекты, закрепляющие

Ti Schottky contact $130 \mu \mathrm{m}$

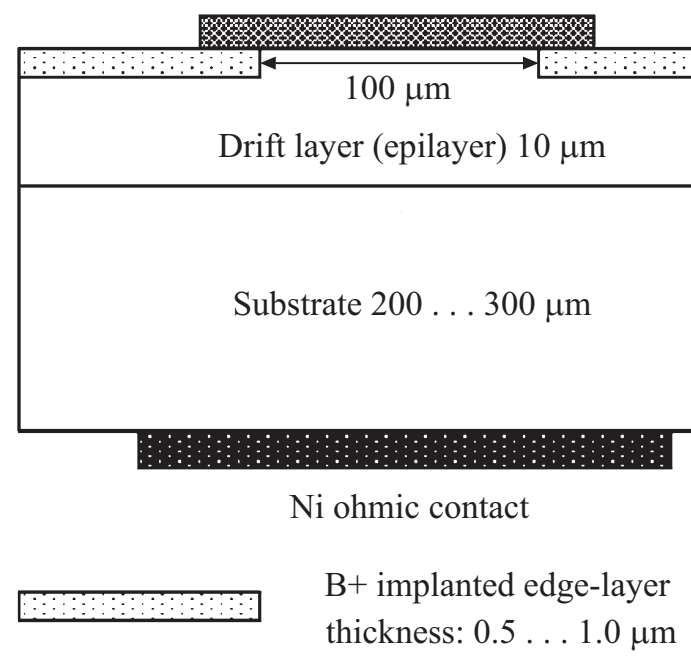

Рис. 1. Конфигурация полевой обкладки с высокоомным имплантированным слоем [4]. 


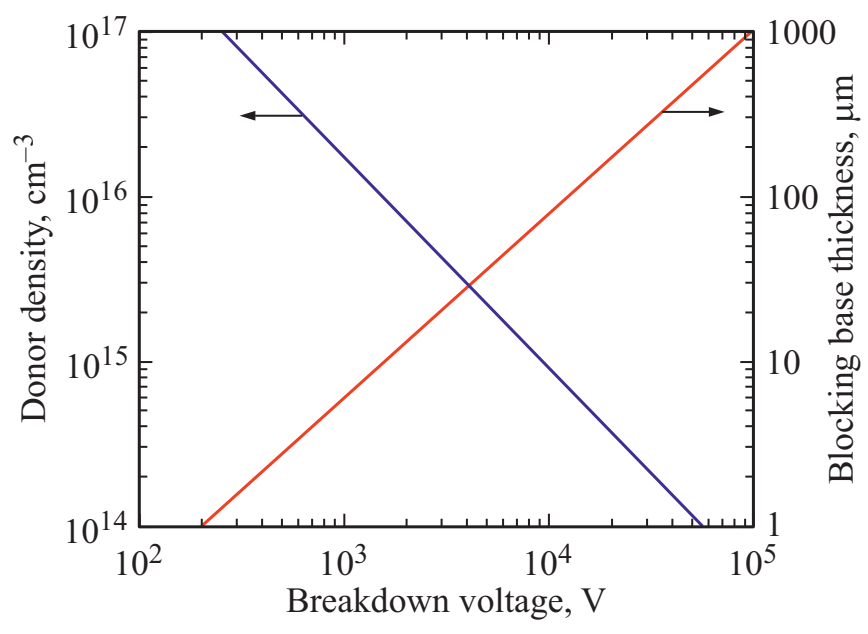

Рис. 2. Зависимости оптимального уровня легирования и толщины $n$-базы $4 H$-SiC ДШ от напряжения пробоя.

$a$

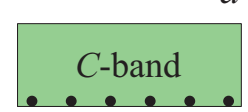

Donors $\oplus \oplus \dot{\oplus} \oplus \dot{\oplus} \oplus \dot{\oplus}$

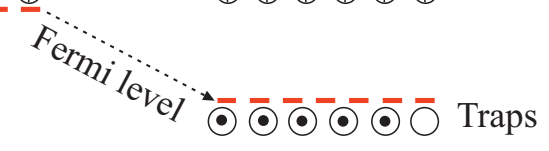

$V$-band

Рис. 3. Механизм компенсации донорной проводимости в $n-4 H$-SiC радиационными дефектами с глубокими уровнями: зонные диаграммы до имплантации $(a)$ и после имплантации $(b)$.

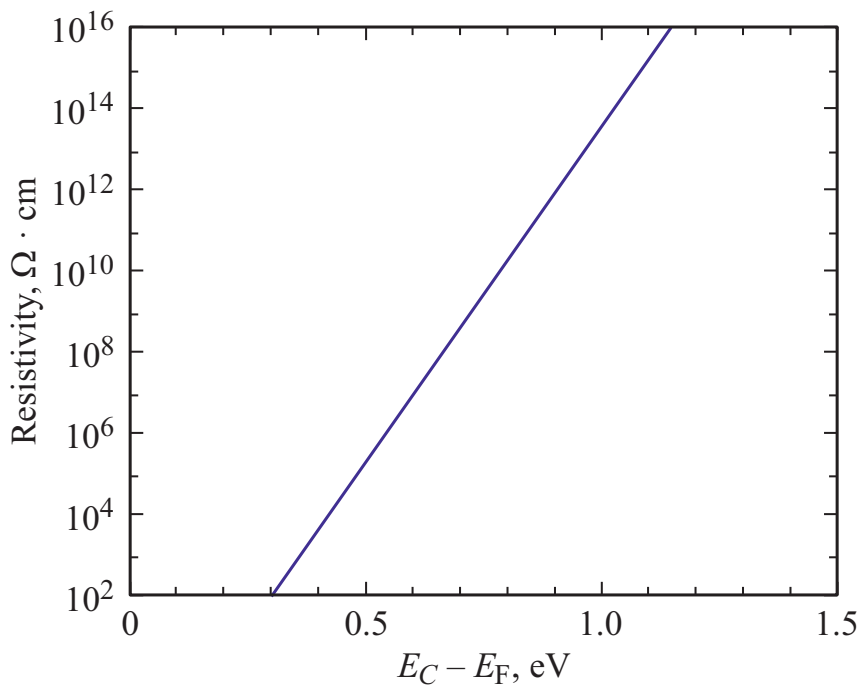

Рис. 4. Расчетная зависимость удельного сопротивления $4 H$-SiC от положения уровня Ферми в запрещенной зоне. положение равновесного уровня Ферми на глубине $1.1-1.2$ эВ ниже дна зоны проводимости $4 \mathrm{H}-\mathrm{SiC}$ (см. рис. 3 и 4). В работе [8] с целью исследования термостабильности введенных облучением ловушек было исследовано влияние термического отжига на электрические свойства облученных слоев. Было установлено, что наиболее высокоомными облученные слои $i-4 H$-SiC становятся после их термообработки при температуре $600^{\circ} \mathrm{C}$. При повышенных температурах слои $i-4 H-\mathrm{SiC}$ остаются высокоомными: удельное сопротивление при температуре $250^{\circ} \mathrm{C}$ составляет $\sim 10^{8} \mathrm{OM} \cdot \mathrm{cm}$.

$\mathrm{B}$ настоящей работе изготовлены $4 H-\mathrm{SiC}$ диоды с молибденовым барьером Шоттки на основе эпитаксиальной $n-n^{+}$(подложка)-структуры (уровень легирования и толщина $n$-слоя $2 \cdot 10^{15} \mathrm{~cm}^{-3}$ и 20 мкм соответственно). Для подавления краевого пробоя в обратном направлении на периферии активной области диодов формировалась полевая обкладка, диэлектрический слой в структуре которой создавался с помощью локальной ионной имплантации 53 МэВ ионов аргона. Для маскирования активных областей диодных структур от облучения на шоттки-контактах локальным гальваническим осаждением выращивались никелевые столбики с вертикальными стенками высотой 10-12 мкм. Измерены вольтамперные характеристики (BАХ) изготовленных диодов. Измеренные характеристики сравнивались с характеристиками контрольных диодов без имплантации. Проанализированы полученные экспериментальные результаты.

\section{2. Экспериментальные образцы диодов}

\section{1. Технология изготовления шоттки-барьерных структур}

Далее кратко описана разработанная нами ранее технология изготовления шоттки-барьерных структур на основе $n-4 H$-SiC (см., например, [9]). Последовательность операций следующая.

1) Термическое окисление поверхности пластины в потоке сухого кислорода при температуре $1150^{\circ} \mathrm{C}$ в течение 9 ч (толщина слоя окисла 60-70 нм).

2) Формирование катодного омического контакта $\kappa$ подложке:

- шлифовка обратной стороны пластины алмазной пастой с размером зерна 3-5 мкм;

- нанесение никеля на обратную сторону пластины ионным распылением никелевой мишени (толщина слоя $\mathrm{Ni}$ $\sim 300 \mathrm{HM}$ );

- термический отжиг никеля в вакууме при температуpe $950^{\circ} \mathrm{C}$ в течение 15 мин.

3) Формирование анодных барьерных контактов с помощью ,взрывной“ ботолитограбии:

- нанесение фоторезиста и формирование в слое фоторезиста окон размером $1 \times 1 \mathrm{Mм}$;

- химическое травление окисла в окнах (в буферном травителе); 
- ионно-лучевое подтравливание поверхности $4 \mathrm{H}-\mathrm{SiC}$ в окнах с помощью ионной $\left(\mathrm{Ar}^{+}\right)$пушки на глубину $\sim 50 \mathrm{HM}$;

- нанесение молибдена на лицевую сторону пластины с фоторезистом электронно-лучевым напылением в высоком вакууме (толщина слоя Мо $\sim 250 \mathrm{Hм}$ );

- удаление фоторезиста с напыленным на него Мо-слоем в органических растворителях;

- отжиг барьерных Мо-контактов в вакууме при темпеpaтуре $600^{\circ} \mathrm{C}$ в течение 2 мин.

\section{2. Формирование металлической маски для ионной имплантации}

Для формирования периферийного облученного контура необходимо надежно замаскировать активную область от потока ионов (рис. 5). Маскирующие элементы должны иметь вертикальные стенки и быть достаточно толстыми для полного поглощения высокоэнергетичных частиц (например, в металлах глубина проникновения $53 \mathrm{MэB} \mathrm{ионов} \mathrm{аргона} \mathrm{составляет} \mathrm{5-7} \mathrm{мкм).} \mathrm{Кроме} \mathrm{сво-}$ его основного предназначения, маскирующие элементы должны иметь хорошие адгезионные характеристики и высокую электропроводность. Далее подробно описана разработанная нами групповая технология формирования маскирующих элементов - металлических никелевых столбиков высотой $\sim 10$ мкм с вертикальными стенками - с помощью локального гальванического осаждения никеля через маску из фоторезиста. Никель является напряженным материалом, поэтому для обеспечения хорошей адгезии был выбран сульфаминовый электролит, из которого осаждаются наиболее пластичные слои никеля. Кроме того, в технологический процесс было введено электрохимическое осаждение (в режиме импульсного тока) тонкого адгезионного подслоя золота.

Последовательность операций следующая.

1) Предварительная подготовка лищевой поверхности перед напылением коммутирующего подслоя (для улучшения адгезии): ионно-лучевое подтравливание поверхности в установке MIMTLA-20 (ускоряющее напряжение $200 \mathrm{~B}$, угол падения ионов $50^{\circ}$ ) на глубину $\sim 10 \mathrm{HM}$.

2) Формирование коммутирующего подслоя: напыление на пластину двухслойного покрытия из хрома (20 нм) и золота (200 нм) термическим испарением в вакууме в установке ВУП-5; в данной комбинации $\mathrm{Cr}$ служит адгезионным, a $\mathrm{Au}$ - высокопроводящим металлом.

3) Защцита тыльной стороны пластины:

- нанесение фоторезиста AZ1518 сплошным слоем;

- ступенчатое задубливание фоторезиста при температуре от 100 до $150^{\circ} \mathrm{C}$ в течение 90 мин.

4) Подготовка поверхности напыленных слоев перед осаждением тонкого адгезионного гальванического слоя: ионно-лучевое подтравливание поверхности в установке MIMTLA-20 (ускоряющее напряжение 100 B, угол падения ионов $30^{\circ}$ ) на глубину $\sim 10$ нм.

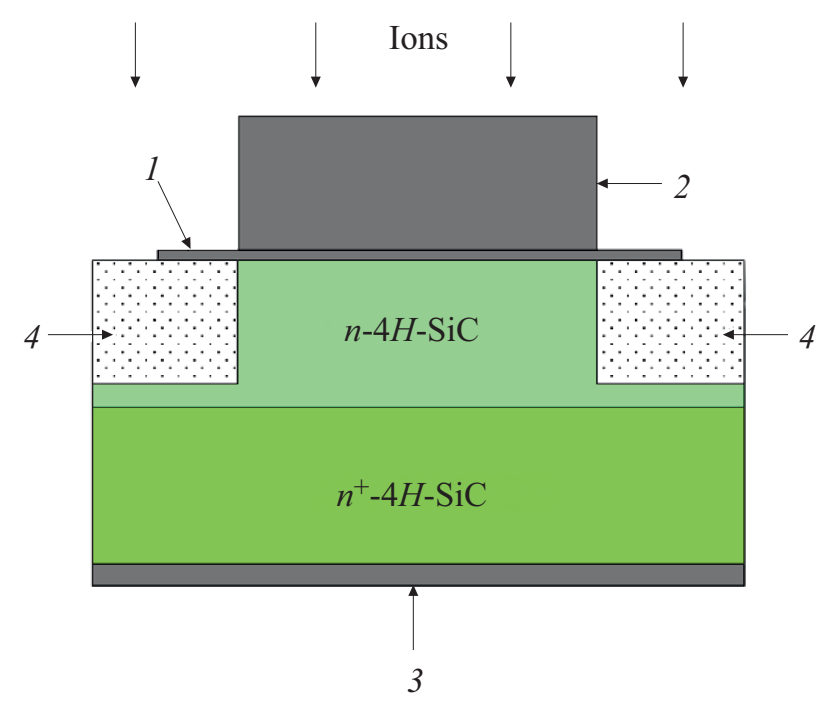

Рис. 5. Конструкция $4 H-\mathrm{SiC}$ ДШ с полевой обкладкой и толстым полуизолирующим слоем, созданным с помощью ионной имплантации: 1 - контакт Шоттки, 2 - маска, 3 омический контакт, $4-i-4 H-\mathrm{SiC}$.

5) Электрохимическое осаждение адгезионного слоя: осаждение сплошного слоя золота (40 нм) в режиме импульсного тока.

6) Формирование маски из боторезиста:

- нанесение фоторезиста AZ4562 сплошным слоем толщиной 20 мкм;

- формирование в слое фоторезиста окон размером $0.9 \times 0.9 \mathrm{мм}$;

- задубливание резиста с плавным подъемом температуры до $70^{\circ} \mathrm{C}$ в течение 180 мин; при таком способе задубливания не происходит оплывания боковой стенки рисунка в фоторезисте, которая определяет форму никелевых столбиков.

7) Дополнительное электрохимическое осаждение адгезионного слоя: локальное осаждение слоя золота (40 нм) в режиме импульсного тока.

8) Электрохимическое осаждение никеля. Использовался электролит следующего состава: сульфамат никеля 300 г/л; хлорид никеля 10 г/л; борная кислота 25 г/л (pH 3-4.5); лаурил (додецил) сульфата натрия 0.1 г/л. Температура осаждения $40-55^{\circ} \mathrm{C}$; катодная плотность тока $\sim 0.1 \mathrm{MA} / \mathrm{Mм}^{2}$; материал анода - никель; скорость осаждения $\sim 0.1$ мкм/мин.

8) Удаление боторезиста в ацетоне.

9) Удаление коммутирующего подслоя ионно-лучевым травлением: ионно-лучевое стравливание сплошного проводящего слоя в установке MIMTLA-20 (ускоряющее напряжение $500 \mathrm{~B}$, угол падения ионов $5^{\circ}$ ).

На рис. 6 представлено электронно-микроскопическое изображение никелевого столбика, осажденного селективно через фоторезистивную маску из сульфаминовокислого электролита, с использованием в качестве коммутирующего слоя напыленного слоя $\mathrm{Cr} / \mathrm{Au}, \mathrm{c}$ последующим удалением последнего ионно-лучевым травлением. 


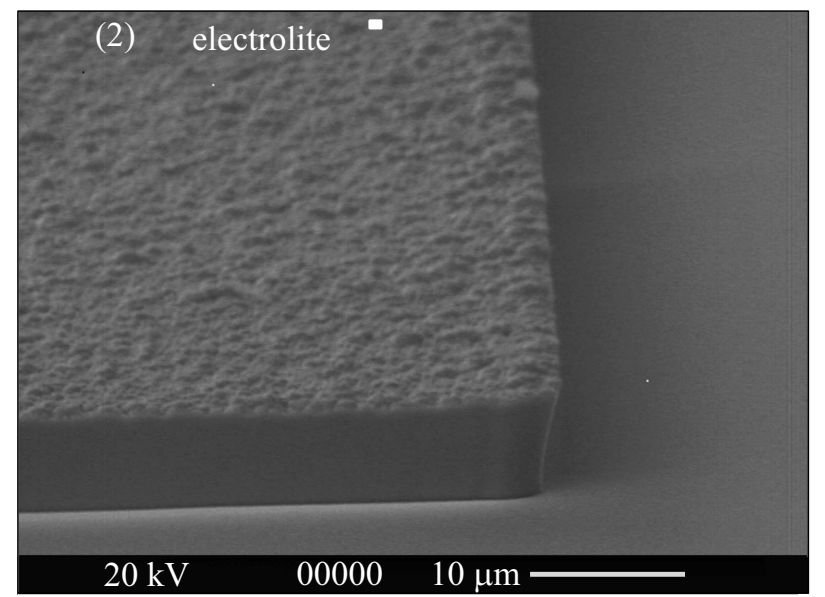

Рис. 6. Электронно-микроскопическое изображение металлического столбика из никеля, выращенного локальным гальваническим осаждением.

\section{3. Ионная имплантация и термообработка}

Облучение проводилось восьмизарядными ионами $\mathrm{Ar}^{+8}$, ускоренными на УНУ „Циклотрон ФТИ““ до энергии 53 МэВ. Пучок ионов фокусировался в узкую горизонтальную полосу, которая сканировалась по площади мишени для выравнивания дозы облучения. Доза облучения - полное число внедренных ионов на единицу площади мишени - определялась по интегральному заряду, приносимому пучком на мишень. После имплантации проводилась термообработка пластины в вакууме при температуре $500^{\circ} \mathrm{C}$ в течение $60 \mathrm{Mин.}$

\section{3. Экспериментальные результаты}

\section{1. Методика измерений BAX}

Для измерений обзорных ВАХ использовался лабораторный высоковольтный (до 4000 В) характериограф. На время измерений пластина погружалась в специальную фтор-углеродную диэлектрическую жидкость во избежание искрения по поверхности при напряжениях $>1000 \mathrm{~B}$.

Для точных измерений $\mathrm{BAX}$ на постоянном токе (в том числе при повышенных температурах) использовался специальный столик, снабженный прижимной иглой и системой подогрева кварцевой лампой до температуры $500 \mathrm{~K}$ (точность поддержания температуры $\pm 2 \mathrm{~K})$. Измерения проводились в вакууме. Прямые $\mathrm{BAX}$ измерялись при токах в диапазоне $10^{-11}-10^{-3} \mathrm{~A}$, а обратные - в диапазоне $10^{-11}-10^{-4} \mathrm{~A}$.

\section{2. Измерения и анализ ВАХ изготовленных диодов}

3.2.1. Сравнение BAX необлученных и облученных диодов. На рис. 7 показаны типичные прямые BAX необлученных и облученных диодов, измеренные при малых токах. Как видно, прямые ВАХ после имплантации практически не изменяются, что свидетельствует о

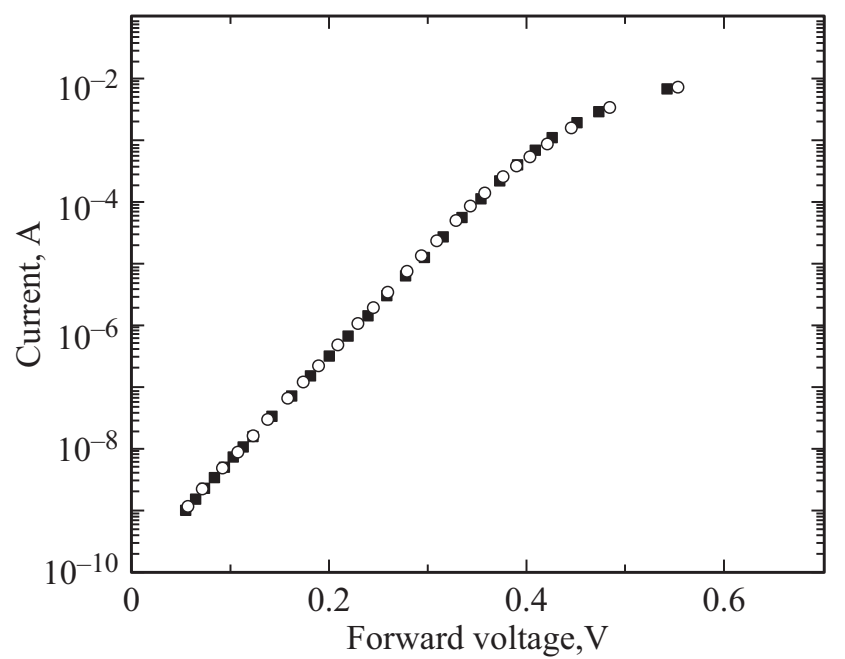

Рис. 7. Типичные прямые BAX необлученных (кружки) и облученных (квадраты) диодов.
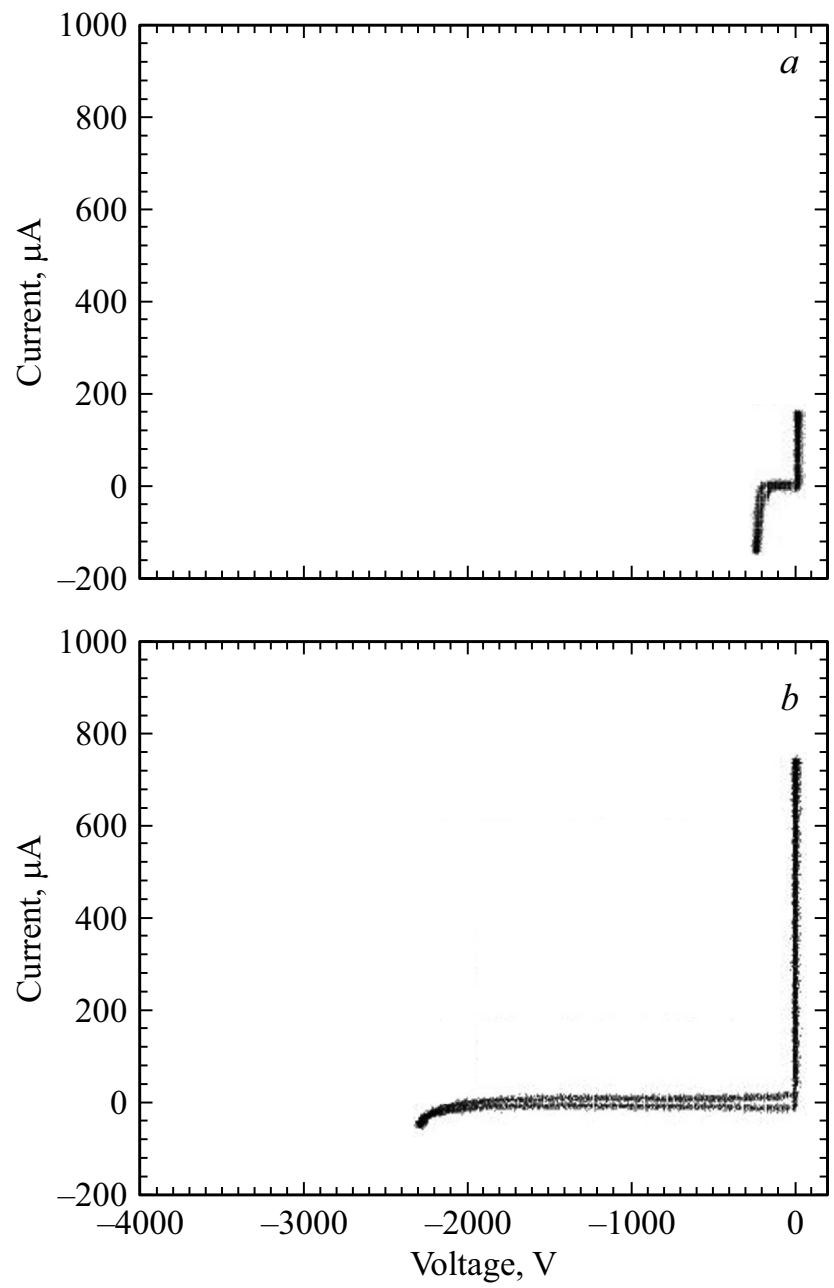

Pис. 8. Типичные BAX необлученных $(a)$ и облученных $(b)$ диодов, снятые с экрана высоковольтного характериографа. 
том, что активная область диодов была надежно замаскирована от облучения. На рис. 8 показаны обзорные BAX необлученных и облученных диодов, снятые с экрана высоковольтного характериографа. Как видно, обратные BAX после облучения кардинально улучшаются: напряжение, при котором начинается заметный рост обратного тока, увеличивается в десять раз: с 200 до $2000 \mathrm{~B}$.

3.2.2. Анализ BAX облученных диодов. Классическая диодная теория (теория термоэлектронной эмиссии) предсказывает для диодов Шоттки следующую зависимость тока $I$ от напряжения $V$ [10]:

$$
I=S A^{*} T^{2} \exp \left(-\frac{\Phi_{B o}}{k T}\right)\left[\exp \left(\frac{q V}{k T}\right)-1\right],
$$

где $q$ - элементарный заряд, $A^{*}$ - константа Ричардсона, $S$ - площадь шоттки-контакта, $\Phi_{B o}$ - высота барьера (в классической теории она считается неизменной), $V$ - приложенное напряжение (положительное для прямого направления и отрицательное для обратного), $T$ абсолютная температура, $k-$ константа Больцмана. BAX реальных диодов Шоттки обычно отличаются от BAX идеализированных диодов. В прямом направлении эти отличия, как правило, не столь значительны, так что прямые BAX можно описать эмпирической формулой

$$
I_{f}=I_{o}\left[\exp \left(\frac{q V_{f}}{n k T}\right)-1\right],
$$

которая отличается от выражения (1) тем, что в ней фигурируют эмпирические величины - ток „насыщения“" $I_{o}$ и коэффициент идеальности $n$. По величине коэффициента $n$ принято судить о качестве диодов Шоттки. Считается, что для хороших ДШ коэффициент идеальности должен быть $<1.1$.

На рис. 9 точками показаны типичные прямые BAX изготовленных 4H-SiC ДШ, измеренные при разных температурах в диапазоне 295-380 K. На участке, предшествующем ограничению тока последовательным сопротивлением блокирующей $n$-базы диода, измеренные ВАХ были аппроксимированы по формуле (2) (в этом случае $I_{o}$ и $n$ выступали в качестве подгоночных параметров). При всех температурах показатель идеальности лишь немногим отличался от единицы: $n \approx 1.02$.

Классическая формула (1) предсказывает, что обратный ток в диодах Шоттки должен насыщаться при напряжениях, составляющих около нескольких единиц $k T / q$ :

$$
I_{o}=S A^{*} T^{2} \exp \left(-\frac{\Phi_{B o}}{k T}\right) .
$$

На практике этого почти никогда не случается, и всегда имеет место довольно значительное увеличение тока с ростом обратного смещения. Утечки могут быть обусловлены дефектами, неоднородностями распределения высоты барьера по площади контакта, конструктивными особенностями диодов, приводящими к преждевременному краевому пробою и др. Но даже в контактах

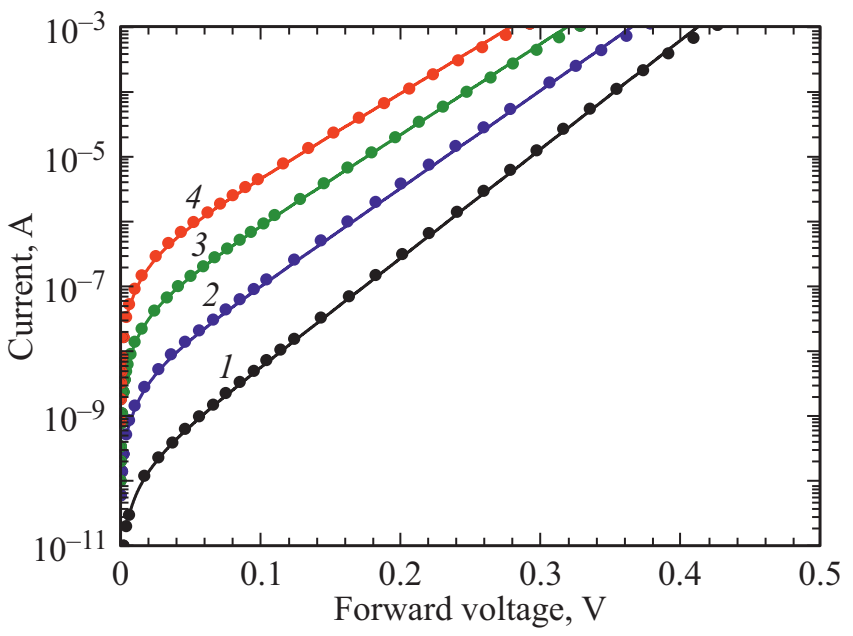

Рис. 9. Типичные прямые BAX Мо-барьеров Шоттки при разных температурах, К: $1-295,2-328,3-353,4-380$. Точки - эксперимент, сплошные линии - аппроксимации по формуле (2).

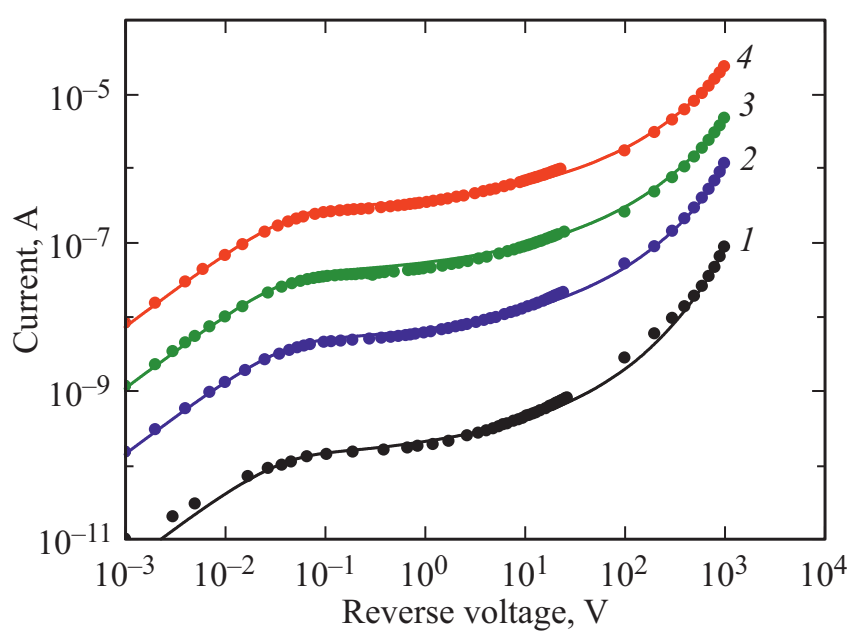

Рис. 10. Типичные обратные BAX Мо-барьеров Шоттки при разных температурах, K: $1-295,2-328,3-353,4-380$. Точки - эксперимент, сплошные линии - аппроксимации по формулам (6)-(9).

с совершенной структурой обратный ток может расти вследствие зависимости высоты барьера от напряжения смещения.

На рис. 10 точками показаны типичные обратные $\mathrm{BAX}$ изготовленных диодов, измеренные при напряжениях до 1000 В в диапазоне температур 295-380 K. В двойном логарифмическом масштабе измеренные BAX выглядят как „мягко“ нарастающие зависимости тока от напряжения: при увеличении напряжения от 0.1 до $1000 \mathrm{~B}$ обратный ток возрастает по меньшей мере на 3 порядка величины. Наиболее вероятный механизм, ответственный за наблюдаемый рост обратного тока это зависимость высоты барьера от напряжения смещения. В классической диодной теории высота барьера 
считается неизменной, однако существуют по меньшей мере две причины понижения высоты барьера с ростом обратного напряжения. Первая причина - это влияние сил изображения на форму и высоту потенциального барьера (эффект Шоттки [10]). Вторая причина - это наличие между металлом и полупроводником тонкого промежуточного диэлектрического слоя, на котором есть небольшое падение напряжения, уменьшающее высоту барьера [11].

Понижение барьера, обусловленное эффектом Шоттки, составляет

$$
\Delta \Phi_{1} / q=\sqrt{\frac{q E_{m}}{4 \pi \varepsilon_{s}}}
$$

где $E_{m}-$ величина электрического поля на поверхности полупроводника. Необходимо сразу отметить, что в ДШ на основе $4 H$-SiC электрическое поле $E_{m}$ может достигать значений $\sim 10^{6} \mathrm{~B} / \mathrm{cm}$ (это на порядок больше по сравнению с диодами на основе кремния и арсенида галлия).

Понижение барьера, обусловленное наличием промежуточного слоя, составляет

$$
\Delta \Phi_{2} / q=\frac{\varepsilon_{s} \delta}{\varepsilon_{\delta}+q \delta D_{s}} E_{m}
$$

где $\delta$ и $\varepsilon_{\delta}$ - толщина и диэлектрическая проницаемость промежуточного слоя соответственно, $D_{s}\left[\mathrm{~B}^{-1} \mathrm{~cm}^{-2}\right]-$ энергетическая плотность поверхностных состояний на уровне Ферми в металле.

С учетом полевой зависимости высоты барьера аппроксимационная формула для обратного тока может быть записана в следующем виде:

$$
I_{r}=I_{o} \exp \left(\frac{\Delta \Phi_{B}\left(V_{r}\right)}{k T}\right)\left[1-\exp \left(-\frac{q V_{r}}{k T}\right)\right],
$$

где

$$
\begin{aligned}
\Delta \Phi_{B} & =\sqrt{\frac{q E_{m}}{4 \pi \varepsilon_{s}}}+\alpha E_{m}, \\
\alpha & =\frac{\varepsilon_{s} \delta}{\varepsilon_{\delta}+q \delta D_{s}} .
\end{aligned}
$$

Электрическое поле $E_{m}$ выражается через обратное напряжение $V_{r}$ в следующем виде:

$$
E_{m}=\sqrt{\frac{2 q N}{\varepsilon_{s}}\left(V_{r}+\Phi_{B o} / q-\Delta_{n}-k T / q\right)},
$$

где $N$ - концентрация доноров в $n$-базе, $\Delta_{n}$ - глубина залегания уровня Ферми в квазинейтральной области $n$-базы.

Аппроксимация экспериментальных обратных ВАХ по формулам (6)-(9) требует подгонки только одного параметра $-\alpha$. Результат этой аппроксимации продемонстрирован на рис. 10 (сплошные линии). Как видно, экспериментальные результаты очень хорошо описываются по формулам (6)-(9) при $\alpha=8 \cdot 10^{-8}$ см (одинаковом при всех температурах). Если предположить, что $\varepsilon_{\delta}=2 \varepsilon_{0}$ для слоя $\mathrm{SiO}_{x}$, то при $\delta=5 \AA$ (один моноатомный слой) получим $D_{s}=5 \cdot 10^{13} \mathrm{~B}^{-1} \mathrm{~cm}^{-2}$. Такие толщины естественного окисла и плотности состояний представляются вполне разумными для реальной поверхности $4 H-\mathrm{SiC}$.

Таким образом, BAX облученных $4 H-\mathrm{SiC}$ ДШ как в прямом, так и в обратном направлении хорошо описываются по модели термоэлектронной эмиссии, если дополнительно учитывается понижение высоты барьера с ростом изгиба зон в полупроводнике.

\section{4. Заключение}

Полученные в данной работе результаты показывают, что полевая обкладка с полуизолятором, создаваемым облучением $4 H$-SiC высокоэнергетичными ионами, может служить эффективной охранной системой для предотвращения преждевременного краевого пробоя в высоковольтных диодах на основе $4 \mathrm{H}-\mathrm{SiC}$.

Важно отметить следующее. В современных высоковольтных 4H-SiC диодах Шоттки на самом деле применяется интегрированная шоттки- $(p-n)$-структура (JBS, Junction Barrier Schottky), в которой шотткиобласти перемежаются с локальными имплантированными р-областями (см., например, [1]). В прямом направлении ток протекает через шоттки-области, так что сопротивление такого диода в открытом состоянии определяется характеристиками контакта Шоттки. В то же время зазоры между р-областями делают такими узкими, чтобы при включении диода в обратном направлении обедненные области от соседних $p-n$-переходов смыкались при некотором напряжении. В результате система $p$-областей действует как экранирующая сетка, благодаря которой область максимального поля находится, в отличие от обычного барьера Шоттки, не в плоскости раздела металл-полупроводник, а несколько отодвинута от поверхности в объем. Поэтому токи утечки, чувствительные к величине поверхностного поля, уменьшаются по величине. Это относится, в частности, и к термоэмиссионному току электронов из металла в полупроводник, величина которого в ДШ на основе $4 \mathrm{H}-\mathrm{SiC}$ сильно зависит от величины поля на поверхности. Ясно, что для $4 H-\mathrm{SiC}$ диодов Шоттки наличие полевой обкладки не отменяет, вообще говоря, необходимость формирования JBS-структуры. В $4 H$-SiC диодах с $p-n$-переходом подобных проблем нет, для таких диодов необходима только высокоэффективная охранная система. Можно надеяться, что разработанный в данной работе способ формирования охранного контура может стать эффективным для биполярных приборов с $p-n$-переходом и продвинуть вперед будущие перспективные разработки и исследования высоковольтных $4 H-\mathrm{SiC}$ приборов с контролируемым лавинообразованием, таких как диодные ограничители напряжения, лавинно-пролетные диоды, импульсные диоды с задержанной ударной ионизацией, ключевые лавинные транзисторы и тиристоры. 


\section{Конфликт интересов}

Авторы заявляют, что у них нет конфликта интересов.

\section{Список литературы}

[1] T. Kimoto, J.A. Cooper. Fundamentals of silicon carbide technology: growth, characterization, devices, and applications (Wiley-IEEE Press, 2014).

[2] D. Alok, B.J. Baliga, P.K. McLarty. IEEE Electron Dev. Lett., 15, 394 (1994).

[3] D. Alok, B.J. Baliga. IEEE Trans. Electron Dev., 44, 1013 (1997).

[4] A. Itoh, T. Kimoto, H. Matsunami. IEEE Electron Dev. Lett., 17, 139 (1996).

[5] M.H. Joo, K.H. Lee, J.H. Song, S. Im. Mater. Sci. Engin. B, 71, 224 (2000).

[6] C.S. Choi, W.Y. Choi, M.H. Joo, J.H. Song, S. Im. J. Vac. Sci. Techn. B, 20, 613 (2002).

[7] П.А. Иванов, М.Ф. Кудояров, М.А. Козловский, А.С. Потапов, Т.П. Самсонова. ФТП, 50, 937 (2016).

[8] П.А. Иванов, А.С. Потапов, М.Ф. Кудояров, М.А. Козловский, Т.П. Самсонова. Письма ЖТФ, 44, 11 (2018).

[9] П.А. Иванов, Н.Д. Ильинская, А.С. Потапов, Т.П. Самсонова, А.В. Афанасьев, В.А. Ильин. ФТП, 47, 83 (2013).

[10] С. Зи. Физика полупроводниковых приборов. Т. 1 (М., Мир, 1984). [Пер. с англ: S.M. Sze. Physics of Semiconductors Physics. V. 1 (John Wiley\&Sons, N. Y., 1981)].

[11] Э.Х. Родерик. Контакты металл-полупроводник (М., Радио и связь, 1982).

Редактор Г.А. Оганесян

\section{High-voltage $4 H$-SiC Schottky diodes with field-plate termination}

P.A. Ivanov, N.M. Lebedeva, N.D. Il'inskaya, M.F. Kudoyarov, T.P. Samsonova,

O.I. Kon'kov, Yu.M. Zadiranov

loffe Institute,

194021 St. Petersburg, Russia

Abstract High-voltage $(2000 \mathrm{~V}) 4 H$-SiC Schottky diodes were fabricated. To suppress the premature breakdown at the edge of diode structures, a field plate as edge termination was applied in which the insulator layer was formed by self-aligned implantation of high-energy $(53 \mathrm{MeV})$ argon specimens into $4 \mathrm{H}$-SiC. For masking the active region of the diodes, $10-12 \mu \mathrm{m}$ thick nickel columns with vertical walls were grown onto Schottky contats by the local electro-chemical deposition. The comparison of current-voltage characteristics of terminated and non-terminated diodes showed that forward of current-voltage characteristics are not degraded after implantation while reverse of current-voltage characteristics are significantly improved. The current-voltage characteristics of the terminated diodes in both forward and reverse direction are well described by the classical thermionic emission model if lowering the Schottky barrier height at high electric fields is taken into account. 